Proceedings

\title{
Inkjet-Printing Polymer Nanocomposite for Detecting VOCs ${ }^{+}$
}

\author{
Mohammad Madhi Kiaee, Thomas Maeder and Juergen Brugger* \\ Microsystems Laboratory, Ecole Polytechnique Fédérale de Lausanne (EPFL), 1015 Lausanne, Switzerland; \\ mohammadmahdi.kiaee@epfl.ch (M.M.K.); thms.maeder@gmail.com (T.M.) \\ * Correspondence: juergen.brugger@epfl.ch; Tel.: +41-21-693-6573 \\ † Presented at the Eurosensors 2018 Conference, Graz, Austria, 9-12 September 2018.
}

Published: 21 December 2018

\begin{abstract}
Polymer nanocomposite (PNC) inks containing polyvinylpyrrolidone with a molecular weight of $40 \mathrm{kDa}$ (PVP40) and a high structure carbon black (CB) were formulated for gas sensing applications. The formulation was optimized for inkjet printing by using a co-solvent system and tuning the ink's viscosity. The Ink loaded with $10 \mathrm{wt}$.\% PVP40, dissolved in a solvent mixture containing $70 \mathrm{wt} . \%$ deionized water and $30 \mathrm{wt} . \%$ gamma-butyrolactone showed an excellent printability. Adding up to $13 \mathrm{wt} . \%$ CB particles to the ink, with respect to polymer content, did not affect its printability. Printing PNC onto the sensor platform and measuring its response towards ethanol, acetone and humidity showed the higher affinity of the PNC to humidity and ethanol.
\end{abstract}

Keywords: Inkjet-printing; polymer nanocomposite; VOC sensor

\section{Introduction}

Selective detection of volatile organic compounds (VOCs) has found many applications in health monitoring, especially for breath analysis [1]. Among different types of devices available for breath analysis, electronic noses (e-noses) are an attractive option considering that they are compact, relatively cheap and simple to operate. E-noses based on metal oxide (MOX) chemiresistive sensors are among devices that are widely studied for breath analysis [2]. However, they require high temperatures for operation, which consequently increases their power consumption. An alternative to MOX-based sensors are chemiresistors based on PNC, which have low power consumption, are easy to manufacture and, due to the wide range of commercially-available polymers, are suitable candidates for applications in e-nose devices [3]. The working principle of such sensors is shown in Figure 1a.

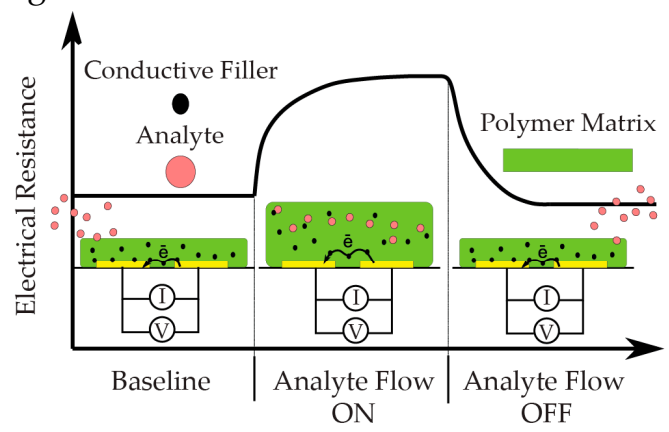

(a)

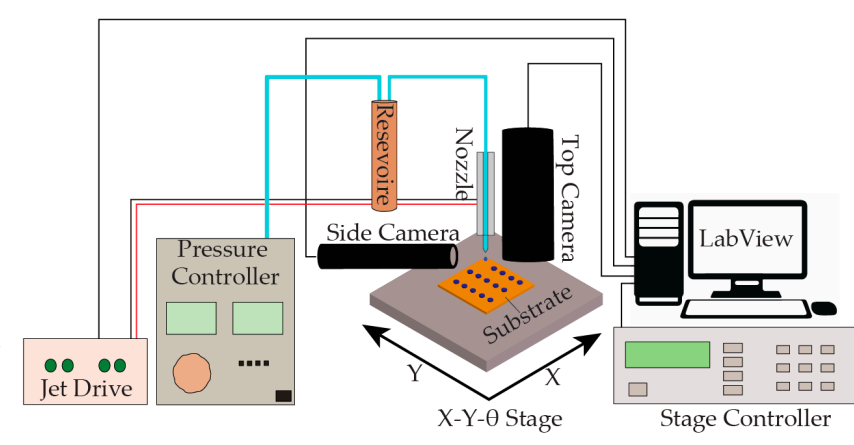

(b)

Figure 1. (a) Working principle of a chemiresistive sensor based on PNC; and (b) schematic of IJP setup that was used in this study. 
Sensors based on PNC have been fabricated by methods such as drop casting, spray coating, and spin coating [4], however recent developments in digital printing have raised a growing interest toward using inkjet-printing (IJP) for fabrication of chemical sensors [5]. This interest is mainly due to the possibility of direct patterning arrays of functional materials onto different substrates [6]. Despite recent advances in printing technologies, formulating inkjet-printable inks remains a challenging task, which is mainly the result of constrains imposed by the print head [7]. Therefore, in order to print a functional material, we first have to establish a systematic process to formulate inks. In this study, we show such a process for formulating printable PNC inks and demonstrate how the printed inks behave when exposed to acetone, ethanol, and humidity, i.e., water vapor.

\section{Experimental}

\subsection{Material and Methods}

Polyvinylpyrrolidone with a molecular weight of $40 \mathrm{kDa}$ (PVP40) was used as the insulating polymer. PVP40 was dissolved in a mixture of deionized (DI) water and gamma-butyrolactone (GBL). DI water has a relatively low boiling point $\left(100{ }^{\circ} \mathrm{C}\right)$ and high surface tension $(72 \mathrm{mN} / \mathrm{m})$; whereas, GBL has a high boiling point $\left(204^{\circ} \mathrm{C}\right)$ and lower surface tension $(44.6 \mathrm{mN} / \mathrm{m})$. Therefore, as will be discussed in the next section, it was expected that the mixture of the two solvents improves the printability of the ink.

Ketjenblack EC-600JD was used as the conductive filler. It is a high structure CB with a high surface area, which makes it possible to obtain conductive composites at relatively low loadings.

Printability of the inks was studied using a Microfab IJP setup, equipped with a print head with an orifice diameter of $80 \mu \mathrm{m}$ that can print inks with viscosity in the range of 1 to $20 \mathrm{mPa} \cdot \mathrm{s}$. The setup is shown in Figure $1 b$.

\subsection{Ink Formulation and Inkjet-Printing}

The optimum concentration of PVP40 in ink, as well as the optimized ratio between DI water and GBL, were determined by measuring viscosity as a function of shear rate using an $A R 2000$ rheometer with cone-on-plate geometry, and subsequent inkjet printing.

After determining printability of polymer solutions, CB was dispersed in the selected ink, using a sonication probe at $13 \mathrm{~W}$ for $5 \mathrm{~min}$. Next, the inks were centrifuged for $1 \mathrm{~min}$ at $13 \mathrm{krpm}$, in order to remove agglomerates and to prevent nozzle clogging. Viscosity measurement was performed again after the dispersion of $\mathrm{CB}$ particles to ensure that the inks remained printable.

To study the effect of CB-loading on the conductivity of PNCs, inks containing $5 \mathrm{wt} . \%, 7 \mathrm{wt} . \%$, $10 \mathrm{wt} . \%$ and $13 \mathrm{wt} . \% \mathrm{CB}$, with respect to polymer content, were prepared and printed onto sensor platforms while the temperature of the substrate was set to $60^{\circ} \mathrm{C}$. The sensor platforms are made of alumina substrates with screen-printed gold interdigitated electrodes (IDE) on top. IJP followed by soft baking at $100{ }^{\circ} \mathrm{C}$ for $1 \mathrm{~h}$ in order to remove the remaining solvent.

\subsection{Sensor Characterization}

The schematic of the characterization setup is shown in Figure 2a where a dilute VOC flow was generated by passing dry nitrogen $\left(\mathrm{N}_{2}\right)$ through a bubbler containing the target analyte. The saturated flow was then mixed with a makeup flow in order to dilute the saturated gas flow. Mass flow controllers were used to control the sample and makeup flow. The makeup flow was set to 1500 $\mathrm{mL} / \mathrm{min}$, and the saturated flow was set to $250 \mathrm{~mL} / \mathrm{min}$. The flow containing the target analyte was guided to the sensors, which had been enclosed inside a 3D printed chamber shown in the Figure $2 \mathrm{~b}$. The resistance measurement was done using a Keithley 2400 source meter. 


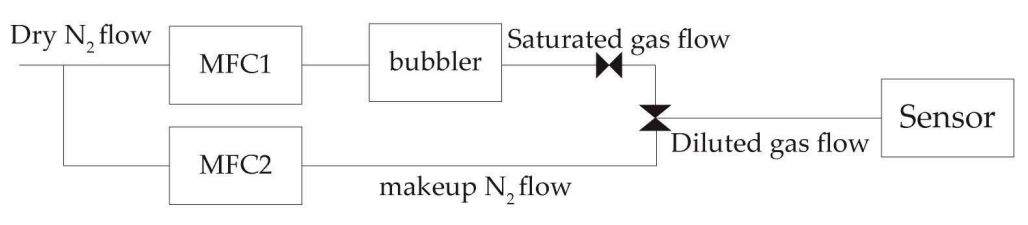

(a)

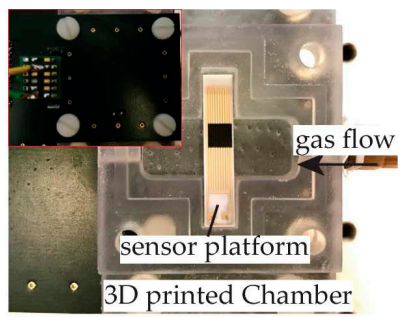

(b)

Figure 2. (a) Measurement setup for characterization of printed sensors; (b) 3D printed test chamber.

\section{Results and Discussion}

\subsection{Inkjet Printing}

The ink containing $10 \mathrm{wt} . \%$ PVP40 dissolved in a solvent mixture containing $70 \mathrm{wt} . \%$ DI water and $30 \mathrm{wt} . \%$ GBL showed the best performance regarding droplet generation and droplet/substrate interaction. Using a binary solvent system containing one solvent with high boiling point and low surface tension (GBL) and another solvent with lower boiling point and high surface tension (water), prevented premature drying during jetting. At the same time, such a solvent system did not increase the initial drying time significantly, which avoided issues such as coffee stain effect.

Printability of the selected ink was not affected by adding CB particles. According to the viscosity measurement shown in Figure 3a, the viscosity increased by higher CB-loading. However, it remained below $20 \mathrm{mPa} \cdot \mathrm{s}$ for up to $13 \mathrm{wt}$ \% CB-loading and as shown in Figure $3 \mathrm{~b}$ stable jetting of the inks could be obtained. Furthermore, the formulation proved to be optimized by printing a uniform layer of PNC onto the sensor platform; where the inter-droplet spacing was set to $100 \mu \mathrm{m}$ with $100 \mathrm{~ms}$ wait time between two droplet bursts, and a substrate temperature of $60^{\circ} \mathrm{C}$. The result is shown in Figure 3c, where PNC containing 7 wt.\% of CB and 93 wt.\% of PVP40 has been printed onto the sensor platform.

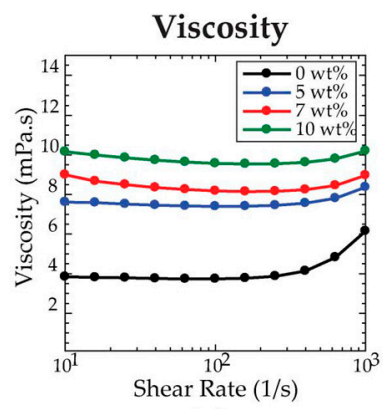

(a)

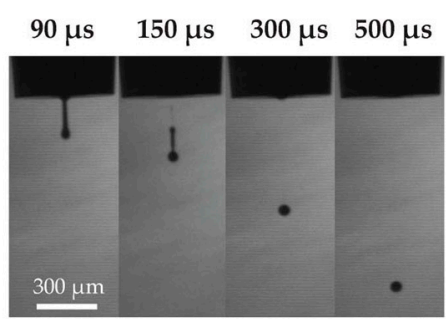

(b)

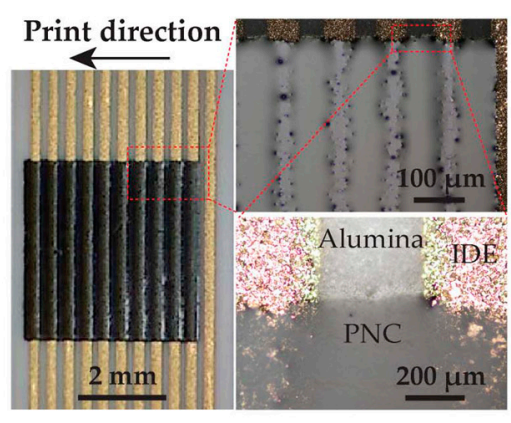

(c)

Figure 3. This figure shows the result regarding ink formulation and IJP of PNC. (a) The viscosity of PNCs as a function of shear rate, the legend shows the weight fraction of CB; (b) Shows formation of satellite free droplets; and (c) shows an optical image of PNC film printed on a sensor platform.

\subsection{Sensor Characterization}

Resistances of the sensors were obtained from I-V measurement under dry nitrogen flow. As shown in Figure 4a all sensors showed a linear behavior up to $1 \mathrm{~V}$ of supplied voltage. Plotting the resistance as a function of weight fraction of CB (Figure 4b) shows that increasing CB-loading from 7 wt. $\%$ to $10 \mathrm{wt} . \%$ decreases resistance by six orders of magnitude, indicating that the percolation threshold is above $7 \mathrm{wt} . \%$. Furthermore, the responses of the sensors containing $7 \mathrm{wt} . \%$ and $10 \mathrm{wt} . \%$ $\mathrm{CB}$ were measured upon exposure to acetone, ethanol, and humidity. Figure 4c-e show the normalized dynamic response of the sensors under $10 \mathrm{~min}$ exposure to analytes, followed by $10 \mathrm{~min}$ of recovery time under $\mathrm{N}_{2}$. 
Based on the results in all cases the sensor containing $7 \mathrm{wt} . \% \mathrm{CB}$ showed a larger response and shorter response time compared to the sensor containing $10 \mathrm{wt} \% \mathrm{CB}$. This can be explained considering that the change in the polymer volume results in a change in the effective $\mathrm{CB}$ content; when the effective CB content drops below the percolation threshold, a sharp increase in response is observed.

Considering the sensor response to different analytes, the response is roughly one order of magnitude larger to water and ethanol compared to acetone. This behavior can be explained since PVP has higher affinity to more polar compounds such as water and ethanol and is actually soluble in them, as opposed to acetone. The response of the sensor as a function of the concentration of ethanol was also studied. As shown in Figure $4 \mathrm{~d}$ by increasing the concentration of ethanol the sensor response increases linearly and, as before, the response is larger for the sensors containing 7 wt.\% CB.

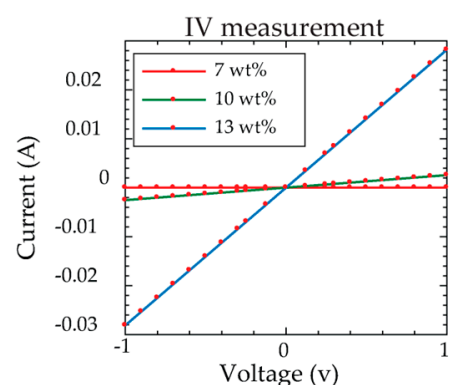

(a)

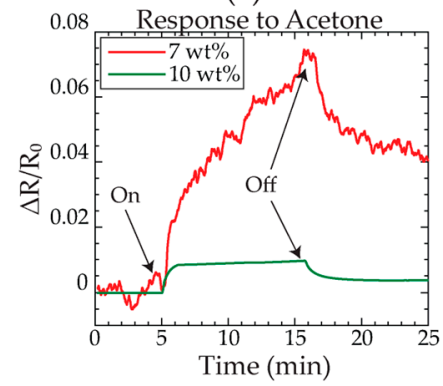

(d)

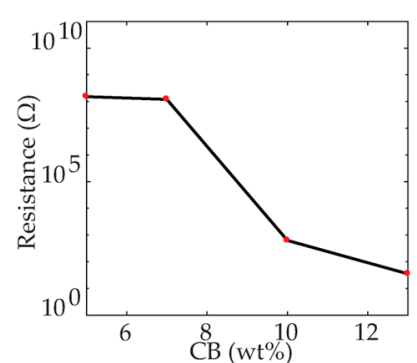

(b)

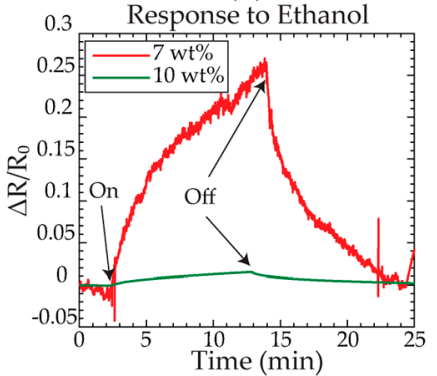

(e)

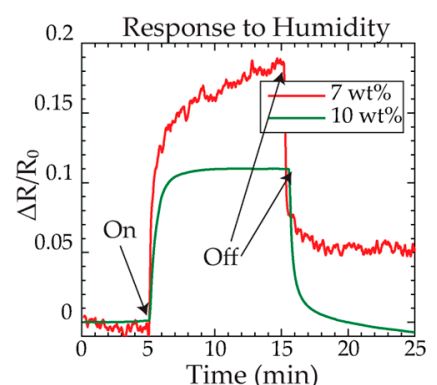

(c)

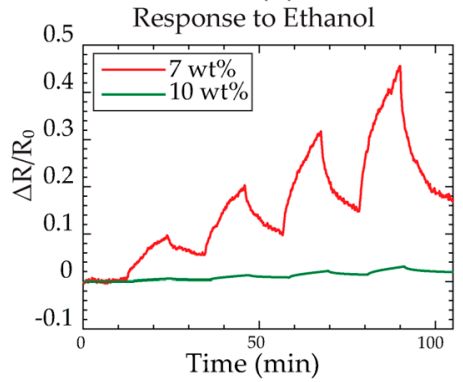

(f)

Figure 4. (a) IV measurement of PNC; (b) Resistance of the sensors as a function of CB loading; (c)-(e) response of the sensors containing $7 \mathrm{wt} . \%$ and $10 \mathrm{wt} . \% \mathrm{CB}$ to ethanol, acetone, and humidity, respectively; and (f) response of the sensors to changing concentration of ethanol.

\section{Conclusions}

We have established a process for inkjet printing of a functional PNC with excellent characteristic for printed e-nose devices that can be applied to different polymer/CB systems. In our approach, we showed in particular that by using a binary solvent system with appropriate physical properties, we could optimize the jetting behavior as well as droplet/substrate interaction, and we were able to print uniform layers of PNC on the substrate for detection of different analytes. This approach will be used for other polymer/CB systems toward fabrication of e-nose devices.

Acknowledgments: This project is funded by Swiss National Science Foundation (SNSF) under contract STCPSR IZLRZ2_163917/1. The author would like to acknowledge Alexey Vasiliev and Ivan Volkov from Moscow Institute of Physics and Technology (MIPT) for the fruitful discussions.

\section{References}

1. Amann, A.; Costello, B.D.L.; Miekisch, W.; Schubert, J.; Buszewski, B.; Pleil, J.; Ratcliffe, N.; Risby, T. The human volatilome: Volatile organic compounds (VOCs) in exhaled breath, skin emanations, urine, feces and saliva. J. Breath Res. 2014, 8, 034001.. 
2. Di Natale, C.; Paolesse, R.; Martinelli, E.; Capuano, R. Solid-state gas sensors for breath analysis: A review. Anal. Chim. Acta 2014, 824, 1-7.

3. Fonollosa, J.; Rodriguez-Lujan, I.; Shevade, A.V.; Homer, M.L.; Ryan, M.A.; Huerta, R. Human activity monitoring using gas sensor arrays. Sens. Actuators B Chem. 2014, 199, 398-402.

4. Arshak, K.; Moore, E.; Lyons, G.M.; Harris, J.; Clifford, S. A review of gas sensors employed in electronic nose applications. Sens. Rev. 2004, 24, 181-198.

5. Mattana, G.; Briand, D. Recent advances in printed sensors on foil. Mater. Today 2016, 19, 88-99.

6. Jacot-Descombes, L.; Cadarso, V.J.; Schleunitz, A.; Grützner, S.; Klein, J.J.; Brugger, J.; Schift, H.; Grützner, G. Organic-inorganic-hybrid-polymer microlens arrays with tailored optical characteristics and multi-focal properties. Opt. Express 2015, 23, 25365-25376.

7. Castrejon-Pita, J.R.; Baxter, W.R.S.; Morgan, J.; Temple, S.; Martin, G.D.; Hutchings, I.M. Future, Opportunities and Challenges of Inkjet Technologies. At. Sprays 2013, 23, 541-565.

(C) 2018 by the authors. Licensee MDPI, Basel, Switzerland. This article is an open access article distributed under the terms and conditions of the Creative Commons Attribution (CC BY) license (http://creativecommons.org/licenses/by/4.0/). 